\title{
Floods and Their Impact on the Environment
}

\author{
${ }^{1}$ Anoud Fawwaz Mohammad Aldardasawi and ${ }^{* 2}$ Beytullah Eren \\ ${ }^{1}$ Faculty of Engineering, Department of Civil Engineering, Sakarya University, Turkey \\ ${ }^{*}$ Faculty of Engineering, Department of Environmental Engineering, Sakarya University, Turkey
}

\begin{abstract}
Resources like air and water are present in the Ecosystem for the benefit of biological life, but a slight disturbance in them results in catastrophic calamities; the flood is one of them. Floods are wrecking threats not only to the life of the individuals but also result in long-term destructions to the economy, environment, and the psychological state of the affected individuals. A slight disturbance in a geographical area's climatic conditions and natural cycles like heavy rainfall and extra precipitation result in floods. Other human activities like over urbanization, deforestation to make residential societies, poor drainage systems, poor number of dams and banks are also the reasons behind such drastic calamities. There are many types of floods, but urban floods are more destructive as they affect highly populated areas, and there are more chances of mortalities in such situations. Floods have broad impacts not only socially and economically but also on the environment. Floods affect the agricultural sector by causing over-saturation, infertility, and soil erosion, damaging the crop fields, especially the winter crops. Flood contaminates the groundwater and makes it impure and improper for drinking purposes. Floods contaminate groundwater with pathogenic microbes and result in water-borne diseases, which have detrimental effects on health. The freshwater's aquatic life is also affected by the disturbance of the natural hydrology of the water. According to some reports, Floods have some positive Impacts on aquatic life as it results in nutrient deposition and favorable habitat for most species. Floods also leave aftereffects on the microinvertebrates like small insects, which are primary role players in the Ecosystem's food chain. So, the floods are a curse for some and a blessing for others.
\end{abstract}

Keywords: Flood, climatic conditions, heavy rainfall, agriculture, groundwater

\footnotetext{
* Corresponding author: Address: Faculty of Engineering, Department of Environmental Engineering Sakarya University, 54187, Sakarya TURKEY. E-mail address: beren@sakarya.edu.tr, Phone: +902642955642
} 


\section{Introduction}

The Ecosystem is made up of two elements: resources and calamities. These calamities are activated when the atmosphere changes, whether it occurs unexpectedly or over time. Many causative factors and the variety of subsequent deformities influence this sudden transition. One of the hazards that results from environmental changes is the occurrence of natural disasters. Fundamentally, natural disasters have occurred since ancient times. A flood is one of the calamities or a natural disaster caused by the overflow of water in a dry region. It is one of the natural disasters accountable for affecting one-third of the population of the world [1].

There are many factors like high rainfall, deforestation due to residential societies, illegal loggings, and drainage overflow[2]. Floods can affect the environment in both positive and negative ways. The aftermath of the floods depends on the size and magnitude of the flood[3]. Extreme floods prove catastrophic for not only the infrastructure, livestock, agriculture, and economy but also on the environmental conditions but if a flood is of small level then there are greater chances that it will have more pros than cons to the environment. The flood can be destructive for the human population but a lucky thing for the natural biodiversity.

Floods are playing a pivotal part in the maintenance of the earth's natural cycles. Floods can be of many types but the prime types of flood are areal, riverine, coastal, and urban flooding. Areal flooding occurs in such areas which have low lying landscape. Heavy rainfall in such low profile areas is the major cause of floods. Overly saturated soil in such plain areas will no longer able to absorb the water and will cause the flooding of water. Riverine flooding occurs in small rivers and streams due to heavy rainfall in the monsoon or due to the melting of glaciers in summers. Rapid flooding mainly occurs in rivers that are located on steep valleys or small rivers. Urban flooding occurs mainly in densely populated areas where due to improper and adequate drainage systems such situations arise. Heavy rainfall results in an overflow of the inbuilt capacity of drainage systems and eventually results in urban flooding and wreak havoc on the infrastructure and livestock of urban areas[4]. Moreover, there are several losses of flood, few of which are mentioned in the table 1.

Table 1. Different priced and unpriced losses caused by the floods [5].

\begin{tabular}{lll}
\hline & Physical and Material Loss & Human Loss \\
\hline Direct Loss & - Direct damage to business present within the flood areas & $\bullet$ Injuries \\
& - Houses & - Deaths \\
& - Automobiles & Utilities and communication services \\
& - Damage to agriculture and animal farming & loss \\
& - Cleaning costs after flood & Panic and unrest \\
& - Damage to utility, transport and communication services $\bullet$ Cultural and historical damage \\
& - Rescue operations & - Environmental disturbance \\
& - Renovation and rehabilitation costs & \\
Indirect Loss & - Damage to businesses located outside the flood affectec & $\bullet$ Psychological damage \\
& areas & - Decrease of trust level on public \\
& - Temporary residence to flood affected people & authorities
\end{tabular}




\section{Materials and Method}

The environmental impacts of floods are evaluated using examples based on the "agricultural conditions, groundwater quality, aquatic biota, micro-invertebrates, the conditions of livestock and wildlife, means of nutrient dispersal and pollutant spreader."

\section{Results}

\subsection{Impacts of flood on the environment}

Floods have a wide range of negative and positive effects, depending on their location, magnitude, depth, and intensity. Individuals and communities are impacted by floods. Floods have social, economic, and environmental implications. The following are the impacts of the flood on the environment:

\subsubsection{Effects of flood on the agricultural conditions}

The economy and the livelihood of the nationals of some countries entirely rely on agricultural lands. Due to flooding, the fertile agricultural land becomes less fertile or infertile due to soil erosion, and sedimentation. The upper fertile soil layer of the cultivable land is washed off with the high-speed flow of the flooding water. The productivity of such agricultural lands is reduced by 40 percent. As water seeps into such flooded land the extra moisture will make the winter season crops difficult to grow. Flooding water affects the nutrient content of the soil leaving it nutrient deficient. Nitrogen is a necessary component needed for the plant defense mechanism. Due to washing off of the fertilizers, the nitrogen is not available to the plants making them susceptible to the pests attack and affecting the productivity of the crops. Stagnant floodwater also weakens the plants and makes them not being able to maintain their posture and eventually leads to their death. So to avoid the aftermath of the flood on agricultural land a proper plan is needed[6].

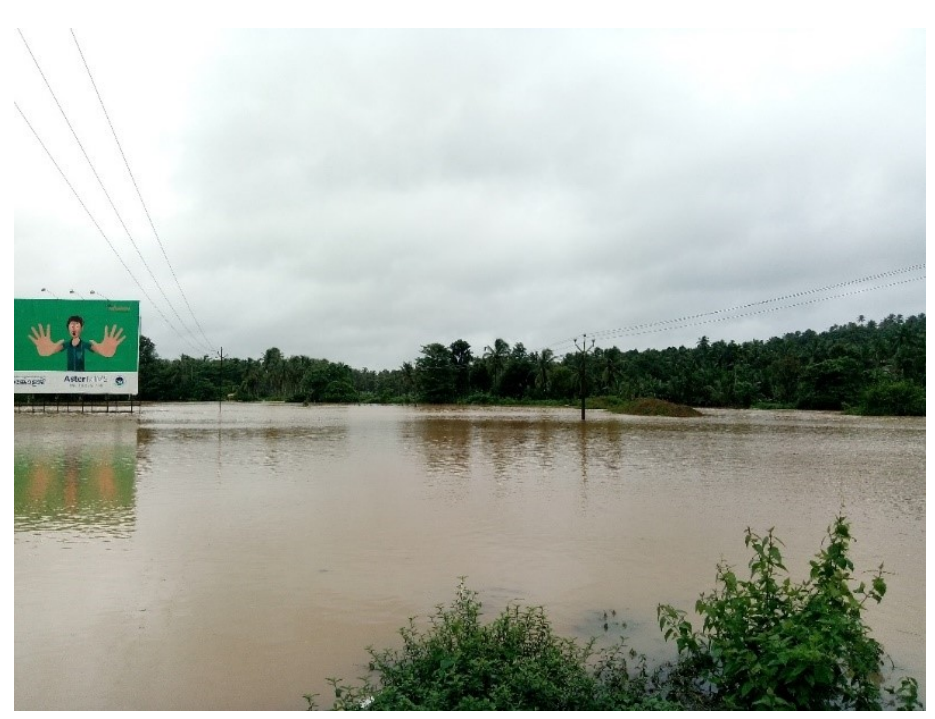

Figure 1. The submerged agricultural land of Malkapuram [7]. 


\subsubsection{Impacts of flood on groundwater quality}

Groundwater is a major part of the geological natural cycles. Groundwater is found underground and moves through aquifers. These aquifers are the primary source of drinking water. Floods are the major cause of the contamination of groundwater[8]. Consumption of contaminated water with pathogenic microbes is the leading cause of water-borne diseases like cholera, typhoid, and diarrhea[9]. Water is a chemical composition of oxygen and hydrogen. Water is the most essential component of the survival of all living organisms. Flood causes the mobilization and deposition of harmful materials like pesticides, pathogens, and other hazardous materials to the rivers, ponds, streams, and groundwater and makes it improper for human use. Flood increases the toxicity potential of lakes, ponds, rivers, and underground water by the chemical that is runoff from industrial and farmland.

\subsubsection{Effects of flood on aquatic biota}

An aquatic ecosystem is majorly impacted by floods. Services that the aquatic Ecosystem provides also disturbed by natural disasters and calamities. Floods have adverse impacts on the aquatic system and all the interlinked services. The probability of risk of floods increases due to gradual changes in the natural water cycles and climate change. The floods have both positive and negative impacts on the aquatic life and aquatic Ecosystem.

Extreme floods change the geomorphology of the rivers. The quality and quantity of aquatic life entirely depend on the geomorphology of the rivers. The harm caused by the geomorphology alterations of rivers has more adverse effects on the organism residing in the aquatic life than the flood itself. Floods prove devastating for the organism habituating the aquatic Ecosystem. The flood can cause their displacement and loss of their habitat[10].

Floods affect the primary productivity of freshwater by changing the clarity, oxygen content, and $\mathrm{pH}$ of the water. Another factor of low productivity of the aquatic system is the mobilization of the nutrient contents[11]. Floods have more positive impacts on the aquatic ecology as it is the reason behind the biodiversity. The aquatic Ecosystem needs floods to increase primary productivity and generate a unique habitat for new species [12]. 


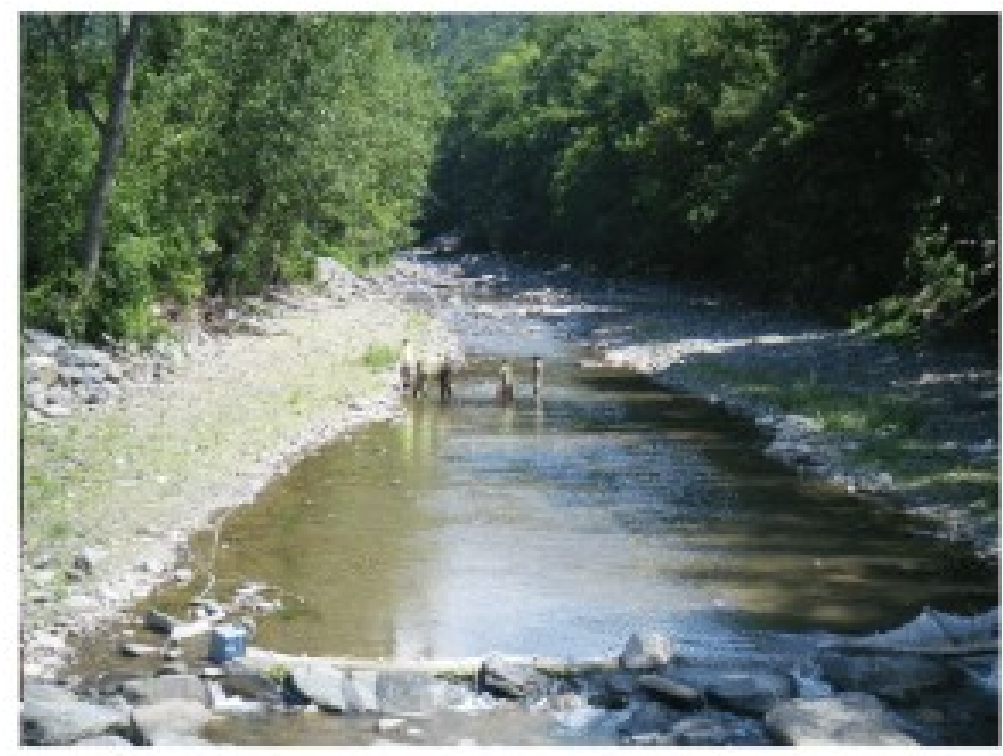

Figure 2. Stony Clove Creek for surveying fish [13].

\subsubsection{Impacts of flood on the microinvertebrates}

The lotic Ecosystem is usually overlooked but this is an integral part of the earth ecology. Microinvertebrates are characterized into grazers, predators, and shredders. Microinvertebrates include swimming and dwelling insects. These macroinvertebrates are crucial in the stability of the food chain as they make the primary steps of the food chain. They act as a bridge between primary producers and secondary ones. They feed on the aquatic debris and later on the birds prey on them.

Extreme calamities like floods and droughts affect the lotic Ecosystem by disturbing the microinvertebrates. A little deviation in the hydraulic flow greatly alters the density of the community of macroinvertebrates indirectly affecting the food chain. The microinvertebrates are highly depressed by extreme floods and result in the dominance of the less stable poorly adapted species of macroinvertebrates [14].
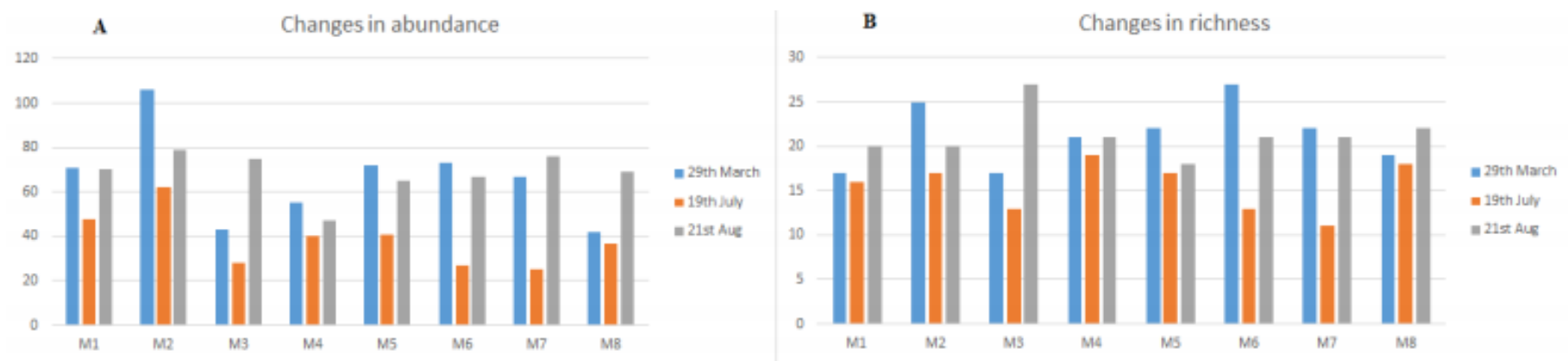

Figure 3. Changes in the abundance of benthic macroinvertebrates after flood (A) and, Changes in richness of benthic macroinvertebrates after flood (B) [15]. 


\subsubsection{Affecting the health conditions of livestock and wildlife}

Flooding may harm wildlife and livestock. Large amounts of water may have a detrimental impact on natural, ranching, and farming-related activities. Such extreme flowing water results in the death of thousands of farm animals. Due to a lack of transportation system, these animals cannot be shifted to upper ground areas and are swept away by floodwaters or frightened to death.

If a flood is intense and extreme enough, it can result in the loss of habitats and biodiversity in the flooded regions. This will render catastrophic effects on the Ecosystem's biodiversity, habitat potential, and food supply, with long-term consequences for surviving wildlife [16].

\subsubsection{Means of nutrient dispersal and pollutant spreader}

Debris, toxins, and even nutrients can all be found in floodwater. Trees, sediments, cement blocks, and even building scraps, bacteria, and pesticides, for example, can travel great distances in floodwater. Sedimentation and turbidity can cause algae and phytoplankton blooms, putting water quality at risk.

Flood water can also disperse essential nutrients and mineral deposits, resulting in increased plant growth and ecosystem health. The nutrients, organic matter, and sediment brought by floodwaters and accumulated on the agricultural landscape over time will help to improve fertility.

\subsubsection{Need of a natural flood management policy}

Natural flood control considers hydrological processes in a river's catchment or along a stretch of coast to decide where the most successful interventions can be introduced, with an emphasis on increasing water retention capacity. There are some examples of such measures, by realigning coastal areas or reconnecting rivers with their floodplains, natural flows can be restored. Wetland preservation will help "slow the flow" of floodwaters by storing floodwater. Reservoirs in agricultural areas can store floodwater during flood events but are otherwise high-nature-value areas. Green infrastructure, such as green spaces and sustainable urban drainage, are examples of urban green infrastructure.

The natural flood management approach yields traditional benefits including reduced risk of harm to society, human health, economic activities, infrastructure, cultural heritage, and the environment. 


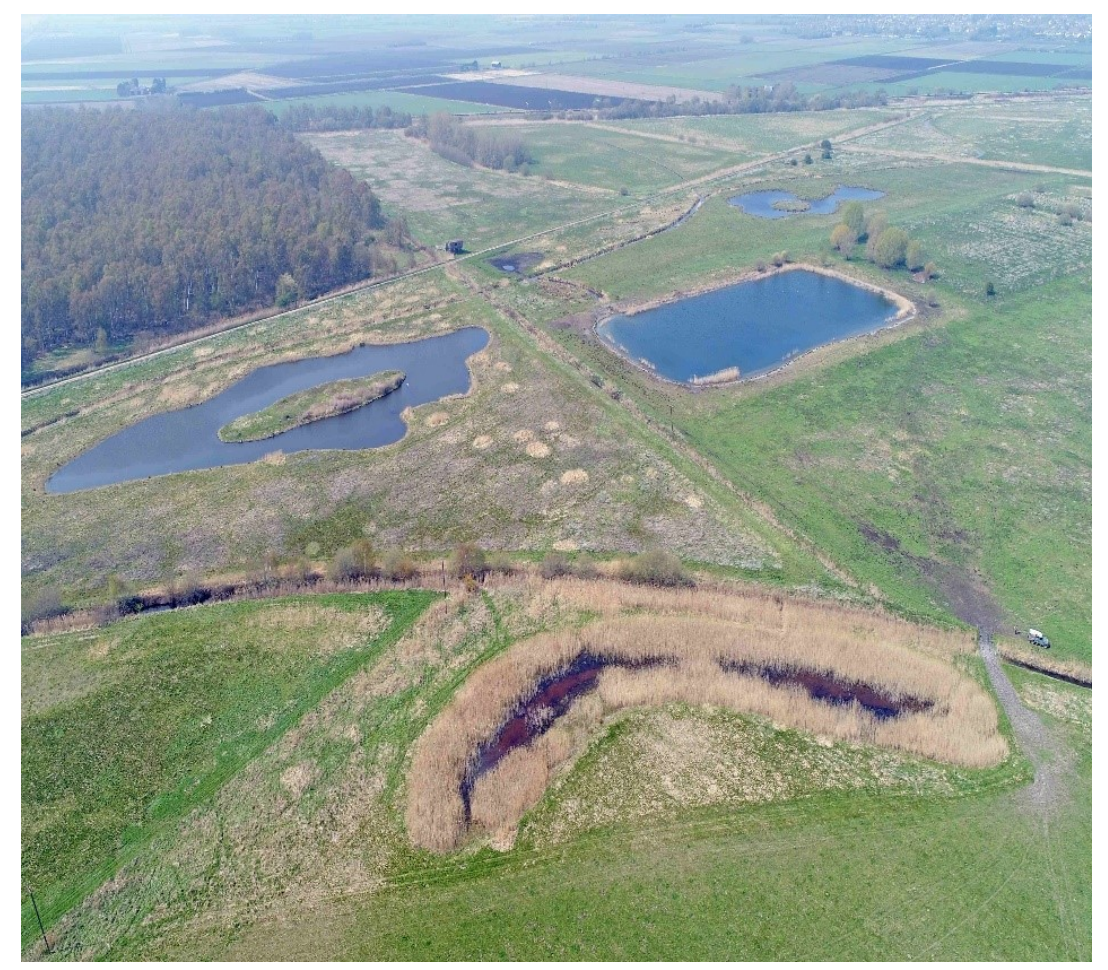

Figure 4. Great Fen depicting new ponds and woods [17].

\section{Conclusion}

Our study leads to the conclusion that impacts of floods cannot be solely characterized as harmful; sometimes they prove to be a blessing for the Ecosystem. The impacts of the flood on the environment are dependent on few factors like the magnitude and depth of the floods. The impacts of the flood on the environment can be reduced by introducing new policies and improving the existing ones. Furthermore, the paradigm of dynamic climate risk management is gathering momentum in a variety of contexts, notably where partners can define a clear range of alternatives and implications [18].

\section{References}

[1] M. A. GHORBANI, H. RUSKEEPAA, V. P. SINGH, and B. SIVAKUMAR, "Flood frequency analysis using Mathematica," Turkish Journal of Engineering Environmental Sciences vol. 34, no. 3, pp. 171-188, 2011.

[2] F. L. Ogden, N. Raj Pradhan, C. W. Downer, and J. A. Zahner, "Relative importance of impervious area, drainage density, width function, and subsurface storm drainage on flood runoff from an urbanized catchment," Water resources research vol. 47, no. 12, 2011.

[3] Y. Hirabayashi et al., "Global flood risk under climate change," Nature Climate Change vol. 3, no. 9, pp. 816-821, 2013. 
[4] D. J. Parker, Floods. Taylor \& Francis, 2000.

[5] M. Haraguchi and U. Lall, "Flood risks and impacts future research questions and implication to private investment decision-making for supply chain networks," Background paper prepared for the global assessment report on disaster risk reduction, 2013.

[6] L. J. O. D. S. Banerjee, "Effects of flood on agricultural productivity in Bangladesh," Oxford Development Studies vol. 38, no. 3, pp. 339-356, 2010.

[7] W. Holland. (2018, 21, June, 2021). Kerala flooding: Agricultural impacts and environmental degradation. Available: https://blog.cabi.org/2018/09/26/kerala-floodingagricultural-impacts-and-environmental-degradation/

[8] H. J. A. a. S. Ghuge, "Floods and Droughts: Effects on Groundwater and Humans (Emerging Refugee Crises)," 2020.

[9] K. Levy, A. P. Woster, R. S. Goldstein, E. J. J. E. s. Carlton, and technology, "Untangling the impacts of climate change on water-borne diseases: a systematic review of relationships between diarrheal diseases and temperature, rainfall, flooding, and drought," vol. 50, no. 10, pp. 4905-4922, 2016.

[10] R. G. Death, I. C. Fuller, and M. G. Macklin, "Resetting the river template: The potential for climate-related extreme floods to transform river geomorphology and ecology," Freshwater Biology vol. 60, no. 12, pp. 2477-2496, 2015.

[11] M. Lindholm, D. O. Hessen, K. Mosepele, and P. Wolski, "Food webs and energy fluxes on a seasonal floodplain: the influence of flood size," Wetlands vol. 27, no. 4, pp. 775-784, 2007.

[12] C. J. Talbot et al., "The impact of flooding on aquatic ecosystem services," vol. 141, no. 3, pp. 439-461, 2018.

[13] C. M. River, "Effects of an Extreme Flood on Aquatic Biota in a Catskill Mountain River."

[14] M. R. Calderon, B. P. Baldigo, A. J. Smith, and T. A. Endreny, "Effects of extreme floods on macroinvertebrate assemblages in tributaries to the Mohawk River, New York, USA," River Research Applications vol. 33, no. 7, pp. 1060-1070, 2017.

[15] S. Chattopadhyay, P. Oglęcki, A. Keller, I. Kardel, D. Mirosław-Świątek, and M. Piniewski, "Effect of a Summer Flood on Benthic Macroinvertebrates in a Medium-Sized, Temperate, Lowland River," Water, vol. 13, no. 7, p. 885, 2021.

[16] C. J. Alho and J. S. J. A. Silva, "Effects of severe floods and droughts on wildlife of the Pantanal wetland (Brazil) — a review," vol. 2, no. 4, pp. 591-610, 2012.

[17] O. BLOG-TEAM. (2019, 22, June, 2021). Natural Flood Management and the role of environmental monitoring. Available: https://www.ott.com/blog/2019/10/natural-floodmanagement-and-the-role-of-environmental-monitoring/

[18] R. L. Wilby and R. Keenan, "Adapting to flood risk under climate change," Progress in physical geography, vol. 36, no. 3, pp. 348-378, 2012. 